\title{
Religious determinant of a person's value-emotional sphere
}

\author{
Shugyla Duanaeva - Yerzhan Kalmakan - Amrekul Abuov - Shuga Abeuova \\ - Tolen Barakbayeva
}

DOI: 10.18355/XL.2020.13.03.03

\begin{abstract}
The purpose of the research consists in revealing the main characteristics of the valueemotional sphere of a person and describing some results of psychological and pedagogical diagnostics, as well as in constructing guidelines for the study of the religious determinants of the value-emotional sphere of a personality. We used the following methods, such as the analysis of the basic concepts of research based on the study of philosophical, psychological, educational, cultural, sociological aspects, literature review, synthesis of partial results, experiment, and interpretation of established scientific data. This study allowed us to obtain the following conclusions: The essence of the concept of "value-emotional sphere of personality" was substantiated, based on the analysis of scientific psychological and pedagogical literature, and the content of the concept of "religiosity" was clarified. Experimental work was carried out among students of 1,2 courses at universities in Almaty, within which they tried to identify the influence of religious determinants on the valueemotional sphere of their personality.
\end{abstract}

Key words: values, emotional sphere, religiosity, personality, Religious determinant, faith

\section{Introduction}

In modern philosophical studies, as well as in religious worldview research, studies of a particular religion as a system, a dynamic whole, a certain socially formed substantiality, consisting of unchanging and changing elements, are beginning to receive special significance. Such developments help to solve the problem of what and how the structure of a particular religion is formed, representing its foundation, holding it together as a whole. Since it is the structure that allows preserving unity with all possible changes and, at the same time, this structure does not lie on the surface, it presents a certain difficulty for research even within the framework of one confession.

However, the polyphony of the modern philosophy of religious situation and the sufficiently large factual material presented by the history of religion, as well as the very fact of combination, coexistence in one topological and temporary space of different religious forms with varying degrees of institutionalization that arose in different historical eras, set a new task for scientists to move from the study of each particular religion as a system to the study of common religious phenomena, as some essential structural elements characteristic of most religious systems. Phenomenologically oriented researchers as well as other philosophers and religious scholars began to deal with these issues in the recent decades. (Alston, 1998; Allport, 1967; Allen, 2005; Blanshard, 1974)

Human practice shows that religion is one of the effective means of regulating the human community. Religion fruitfully contributes to the observance of socio-ethical institutions, both by individuals and social structures. If we analyze the events that took place in the history of mankind, but also those taking place in the present (both in the East and West), we will find ample evidence of this. In this regard, the question arises about the main essence of religion. What are its functions, besides those that are well known in the theory of religion and religious studies, how can we assess the phenomenon of religion as a social worldview, and why is this phenomenon so 
widespread still in the era of modern technology when the scientific worldview became dominant? The relevance of identifying the basic ideas about the essence of religion in modern Western and Muslim philosophy and comparing them is primarily due to the need to find the answers to these questions that confront intellectuals of all types of modern societies.

In addition, in connection with the aforementioned state of religion and religious worldview in modern society, the relevance of the topic of our research can be explained by the following reasons: first, as is commonly known, a modern person feels spiritually powerless in the scientist world. Science and technology teaches one to doubt spiritual values, surrounding one instead with material things and pleasures of this world. Naturally, such a person inevitably becomes a calculating creature, considering even those closest to him only as means to achieve his goals. Such a person destroys the integrity of his worldview, thus losing the main goal for which one needs to live.

Secondly, the new scientific thinking deprived a person of that religious picture of the world that has functioned for millennia and gave him universal knowledge about how to live and what are the fundamental moral principles of the world order. At the same time, destroying the naive-holistic view of the world that is given by religion or religious philosophy, scientific thinking did not give in return the same holistic understanding of the world, because all the concrete truths of science cover only a fairly narrow collections of phenomena. Science taught man to doubt everything and gave rise to a worldview emptiness around itself. Science alone is not able to fill this emptiness, this existential void, because it is also a matter of philosophy and religion.

Thirdly, it is well known that science is the greatest achievement of human culture. It helps to facilitate the life of a person, providing him with material and emotional benefits. But deified science, according to many scientists, is a completely different phenomenon, which leads to a completely opposite result. Science should be considered only as one of the many existing spheres of human culture, which has its own specifics and its tasks. Science itself should not be considered the highest value of human society, for it, like all other spheres of culture, is only a means in solving various problems of human existence. In a civilized society, there must be, at the same time, a place for science, and for art, and for philosophy, and for religion, and for all other elements of human culture. (Braithwaite, 1955)

In the light of similar phenomena occurring in the scientific world, there is an urgent to identify and evaluate ways to solve the problem of the place of religion in the worldview of modern man and modern society. One way of achieving this is by studying the ideas of modern Western and Eastern philosophers and generalizing their ideas for practical application.

The concepts of "philosophy" and "religion" have always been in the focus of attention of philosophical thinking. Modern philosophy is characterized by special attention to the problems of the interaction with various spheres of public life, as well as to the study of the mechanisms of the influence of culture on social processes, human consciousness and behavior. Along with the actualization of sociocultural issues, twentieth-century society is experiencing a kind of "religious renaissance." In light of this, the interaction of culture and religion needs an in-depth and comprehensive analysis that can identify new points of contact, the possibilities and boundaries of their constructive influence on traditions, innovations, worldviews, and lifestyles of man and society.

The social experience of the twentieth century, as well as the experience of cultural creativity, became the basis for a serious enrichment of the content of the concepts of religion used in philosophical, theological, scientific, and artistic discourses, as well as in the practices of everyday consciousness. The ideas of culture-centrism and religious universalism as a model for explaining reality, ideas about the role of

XLinguae, Volume 13 Issue 3, June 2020, ISSN 1337-8384, ISSN 2453-711X 
religion in counteracting cultural degradation, and revising the status of religion in society in the light of the liberalization of cultural values due to the significance of their influence, require special philosophical reflection.

The study of the content of these concepts of religious philosophy is of particular importance, since, on the one hand, this philosophy has experienced the influence of religious and cultural modernism, while preserving, on the other hand, axiological conservatism and fidelity to the canonical traditions of thinking. Nevertheless, experiencing this internal tension, the religious philosophy of the twentieth century seeks to modify religious worldview, adapt it to the realities of modern culture, and the growing needs and demands of man. These searches are consonant with the efforts of secular philosophy aimed at creating a new worldview that can indicate a humanistic vision and preserve cultural traditions. Such a humanistic approach could constitute a way out of the crisis of modern civilization. A philosophical analysis of the content of the concepts of religion and culture is able to contribute to the formation of a healthy conservatism of the mass consciousness: rejecting nihilism in culture, while strengthening immunity to the destructive tendencies of postmodernism, and its revision of the ideals of humanism.

In the social life of modern Kazakhstan, there is a clear tendency to strengthen the role of religion. This is manifested in cooperation with institutions of power and secular organizations, in the revitalization of traditional and modernist cults of various kinds, and in the overall growth of the general religiosity of the population. The spread of traditional religion is associated with the revival of the spiritual and moral foundations of society. Thus, religiosity becomes an essential element of people's consciousness and an effective regulator of their behavior.

Under these conditions, the problem of tolerance and mutual understanding among believers and with people of other faiths (or no faith) is acute. The well-being of society depends largely on the successful cooperation of representatives of different religions and unbelievers.

An important basis for solving this problem is the knowledge of the psychological characteristics of a religious person. Therefore, the study of the specifics of the valueemotional sphere of the individual in the context of a religious determinant is relevant. The purpose of the research is the study of the religious determinants of the valueemotional sphere of personality

To achieve the goal, the following tasks were formulated:

1) to identify the specifics of the value-emotional sphere of the personality;

2) to study the peculiarities of the value-emotional sphere of the personality empirically;

3) to determine the influence of religious determinants on the value-emotional sphere of a person.

\section{Research questions:}

- What is a person's value-emotional sphere?

- What impact does religious determinant make on a person's value-emotional sphere?

In the psychology of religion, little attention is paid to the problem of religious values. With the emergence of the psychology of religion as an independent discipline, the interest of scientists focuses mainly on the emotional-sensual sphere of personality. This can be clearly seen in the works of such famous psychologists of the beginning of the 20th century as William James (1917), T. Ribot (2002), T. Flurnua (2001), and others. The main subjects of the research were religious experiences and religious feelings (James, 1917).

The interest of scholars in the emotional-sensual sphere of a religious personality has not faded away throughout the entire twentieth century, as evidenced by the large 
amount of scientific literature devoted to this issue (Ignatenko, 2001), (Kutsenyuk, 2007), (Maslow, 2013), (Lovinger, 2000). The problem of the value-emotional sphere of the religious personality remained at the periphery of research.

Weak attention to the value aspects of the inner world of a religious person is unjustified because they are the essential features of a religious person, determining their moral character and being. The idea of a religious personality will be superficial and inadequate in reality, since the main transformations of the inner world of a person under the influence of religion concern precisely the value-emotional sphere. This does not mean a complete lack of value-related research in the psychology of religion. It was revealed in the context of empirical studies of the values of the individual in foreign psychology.

The greatest influence on this issue in foreign psychology was provided by research conducted by the American scientist G.W. Allport (1963). Applying the ideographic method to the analysis of personal values, Allport designed a questionnaire that revealed the personality value types (Allport, 1963). The scholar took the typology put forward by the German philosopher and psychologist E. Spranger, where he attempted to translate the gathered data into a standardized format, highlighting the corresponding scales. In the typology of E. Spranger, each of the six "ideal" types of personality is distinguished depending on its values and interests (Spranger, 1928). Translating this typology into a standardized language through factor analysis of the data obtained on the basis of the questionnaire, G.W. Allport identified a series of scales, one of which was the so-called Religiosity Scale (RS) (Allport, 1963)

The introduction of the Religiosity Scale entailed further numerous empirical studies of religious values, but the Scale itself became the subject of study and refinement. So, in his study R.A. Hunt showed that "The Religiosity Scale mainly measures the involvement of the individual in traditional religious institutions to give meaning to their lives." (Hunt, 1998: 272) In D. Heath (1993) study, the Religiosity Scale also underwent a differentiation. The data obtained from it formed two clusters expressing:

1 - the coefficient of traditional religious beliefs ("Traditional Belief Index");

2 - religious and philosophical coefficient ("Religious-Philosophical Index"), and the high values of the latter indicator were associated with the danger of psychological disorders.

Many empirical studies are devoted to establishing the correlation of the Religiosity Scale with other scales. In the research of E.G. Nolan, P. Bram, and M.E. Heintzelman, the Religiosity Scale was negatively correlated with the so-called California F scale (California F scale). W. Eckhardt found a positive connection between the Religiosity Scale and the "Punitiveness factor" in militaristic, conservative, nationalistic, open, and misanthropic societies. Hogg and Vaughan (1995) argues that high values on the Religiosity Scale predict a person's social compliance. High values on the Religiosity Scale also mean the severity of the dogmatism of the personality, which was manifested in the correlation between these factors in the research of M.V. Jones and I.R. Juan with employees.

The opinion of R.I. Evans is important in this respect. He claims that the Religiosity Scale does not show the difference between people who are religious in the sense of humanistic convictions and those whose piety is relatively limited and ethnocentric. Due to the lack of a clear internal differentiation of the Religiosity Scale, it is impossible, for example, to unequivocally argue that a religious person is always dogmatic, despite the identified positive correlation between these factors (Evans, 2003; Chisholm, 1997).

Religiousness as a phenomenon is a religion reflected in the consciousness of believers of individuals and manifested in their practical actions, the subjective side of religion, its concrete manifestation in the individual and group consciousness of

XLinguae, Volume 13 Issue 3, June 2020, ISSN 1337-8384, ISSN 2453-711X 
believers, a certain degree of individual's commitment to religion formed in his consciousness.

V.P. Barannikov and L.F. Matronina (2014) focus on the socio-psychological aspects: religiosity is a socio-psychological characteristic of the individual, a way of social self-identification and social adaptation (Barannikov - Matronina (2014).

The concept of "religiosity" in psychological science is most clearly analyzed in contrast to other concepts of religious and psychological phenomena, such as religious faith, religious consciousness. The signs of religiosity are highlighted. Domestic and foreign authors came to a common opinion on the structure and described its characteristics (i.e., level, character, direction). (Prat, 2008)

Moreover, religiousness is an integrative phenomenon. In its structure, the majority of researchers distinguish three main components.

1. The cognitive component - religious knowledge, beliefs, presuppositions, ideas.

2. Emotional component - feelings, emotional experiences associated with religion. Among them are both positive (reverence, joy, etc.) and negative (fear, religious intolerance, bias, etc.); mystical.

3. Behavioral component - actions to practice a religious cult, non-cult behavior, and the conversion itself.

According to the new approach proposed by E.A. Khodzhaeva and E.A. Shumilova, (2003) when considering religiosity, it is necessary to analyze two more components, namely (1) identification (awareness of a person of a particular denomination) and (2) normative value (interiorization of norms and values reported by religion, desire to follow them in everyday life, desire to distribute them). The authors emphasize that religion is holistic; the components are closely interconnected and interdependent.

\section{Methods}

The survey method was used in the study. The participants of the survey were given a questionnaire in which they were asked to answer questions related to a person's value-emotional sphere. The items used in the questionnaire were prepared according to the related literature and interview results conducted with some students. Descriptive and inferential analyses were conducted to get a deeper insight into the research questions. The time limit was 90 minutes for the survey.

What follows is a list of research methods used in our study:

- Literature review on psychology, religion studies, psycholinguistics in the framework of the problem being investigated;

- Observation of the educational process for the purpose of studying the facts that contribute to a more successful person's value-emotional sphere process;

- Questionnaires,

- Experimental training, and the method of statistical processing.

- In addition, statistical data processing methods were used: 1 chi-square (\%), L. Sachs criterion (Z), Mann-Whitney criterion (U), Student's t-criterion, Spearman's rank correlation coefficient (rs)

\section{Participants}

The study was done on a group of a hundred fifty undergraduate learners in the BA degree of different universities in Almaty city. Most of the students were juniors (48 $\%),(52 \%)$ were seniors. In terms of gender, the students were not balanced with 122 Females (81\%), 28 males (19\%), and their age ranged from 18 to 21 . The reliability of the obtained results of the research was ensured by adhering to the initial methodological and theoretical principles, using a set of standardized methods corresponding to the subject, goals, and objectives of the study; representativeness and sufficient sample size; empirical testing of hypotheses; statistical significance of the results. 


\section{Discussion of the Implemented Method}

The method of the research of the religious value-emotional sphere is a modification of the methodology for studying the value orientations of an individual "VOP-8," developed by G.E. Leevik (2000). The "VOP -8 " method is a questionnaire that reveals the basic value judgments of a person. In its content, we included statements aimed at identifying religious value-semantic orientation (Leevik, 2000).

It should be emphasized that the method of the research of the religious valueemotional sphere diagnoses not the real values of the individual, but the expressed value-emotional sphere. At the same time, the expressed orientation of the personality may differ from the real values manifested in its behavior, which has been confirmed by many studies. (Miedema, 2014)

The method is a set of statements relating to various aspects of the individual's religious experience and revealing the content of the religious value-emotional sphere. The subjects are asked to evaluate the significance of these statements on a 7-point scale (from 1 to 7). The VOP-8 technique is easy to use and allows you to quickly collect the necessary material. The VOP-8 questionnaire was applied holistically, but only statements characterizing the religious value-emotional sphere were analyzed.

One group of these statements is structured in such a way as to correspond to the fundamental components of the inner world of the personality - the sphere of relations, the emotional, semantic sphere of the personality and self-consciousness. These are statements:

1. "Have a deep personal relationship with God."

This statement allows you to diagnose the significance of God for a person of religious faith as a psychological phenomenon.

2. "Feel the action of God in your life" (emotional sphere). This statement reveals the emotional content of a person's relationship with God in connection with the manifestations of the Divine in a person's life.

3. "To have spiritual support in God." The search for inner spiritual support (psychologically - the search for the meaning of life) is a common motive for a person to turn to religion. Therefore, identifying the significance of this aspect of a person's life seems necessary.

4. "To realize oneself as a believer" (self-consciousness). This statement is aimed at diagnosing the value-emotional component of a person's religious self-consciousness.

5. "To be able to communicate with God." The person's communication with God is expressed in the form of prayer.

6. "To know, to discover the Divine truths" (knowledge). Cognition is in the form of revelation, contemplation of Divine truth.

7. "To do deeds in the name of God." The human activity framed as a service to God.

8. "Strive for spiritual purity, keep the commandments of God" (morality). Since moral perfection (striving for spiritual purity and righteousness) is one of the priorities of the individual life of the believer, the introduction of this statement seems to be reasonable.

9. "To be closer to God." The statement summarizes previous utterances and is of psychological nature. Its introduction is necessary to establish a correspondence between the psychological level of a religious value-emotional sphere (to realize, feel, have relationships, etc.) This statement indicates the level of consistency in between components of the religious value-emotional sphere.

In the course of the study, we abandoned the "VOP- 8 " method proposed by the author for converting the "raw" values obtained according to the stated assertions into standard ones. This procedure is very cumbersome and requires a quantitative analysis of the values obtained for all the other 50 allegations of "VOP-8," which would make the study difficult. Therefore, we chose to interpret the results in raw values and use the appropriate statistical tools for this case. Thus, the modification carried out in

XLinguae, Volume 13 Issue 3, June 2020, ISSN 1337-8384, ISSN 2453-711X 
accordance with the objectives of our study expanded the possibilities of the VOP-8 methodology by G.E. Leevik, and also allowed us to measure the indicators of interest.

\section{The Results of the Study}

The results of the study of the religious value-emotional sphere (RCES) are presented in Table 1. The table contains statements, the significance of which the subjects evaluated on a 7-point scale. The statements reflect this or that sphere of the inner world of the individual and the sphere of activity (being) in which the religious valueemotional sphere is realized. As we see, for students with a high level of religiosity, there is a high significance of the religious value-emotional sphere (total RVES $=6.41$ points, $o=0.6$ ). This means that their basic life meanings are determined by religion. This result is quite expected in this category of subjects. Verbally expressed religious value-emotional sphere is a necessary internal condition for the choice of a spiritual life path.

\begin{tabular}{|l|c|}
\hline \multicolumn{1}{|c|}{ Religious value-emotional sphere (RVES) } & $\begin{array}{l}\text { Expressiveness } \\
\text { of RVES }\end{array}$ \\
\hline 1. "Have a deep personal relationship with God" & 6.41 \\
\hline 2. "To feel the action of God in your life" & 6.20 \\
\hline 3. "To have spiritual support in God" & 6.80 \\
\hline 4. "Realize Yourself a Christian" & 6.37 \\
\hline 5. "To be able to communicate with God" & 6.54 \\
\hline 6. "To know, to discover the Divine truths for themselves" & 6,22 \\
\hline 7. "Doing deeds in the name of God" & 6.09 \\
\hline 8. "Strive for spiritual purity, keep the commandments of God" & 6.50 \\
\hline 9. "To be closer to God" & 6.57 \\
\hline The total indicator RCTS & 6.41 \\
\hline
\end{tabular}

\section{Table 1. Religious value-emotional sphere of personality}

At the same time, as the standard deviation shows, this group of subjects can be characterized as homogeneous - a high degree of manifestation of the religious valueemotional sphere is characteristic of all. The calculation of asymmetry and kurtosis was carried out according to the formulas of E.I. Wasteland. This method of calculation requires finding critical and empirical values for a particular distribution. The distribution is considered normal if the obtained empirical values of the asymmetry and kurtosis modulo show less than the critical values. For our group, the empirical values of asymmetry and kurtosis are: $\mathrm{Amp}=-1.483 ; \mathrm{H}=1,958$. Critical values: $\mathrm{A}, \mathrm{f}=1.027$; Ecr $=3.076$. $|\mathrm{AEMP}|>\mathrm{A} \wedge$, $\mid$ EEMP $\mid<$ Ecr. As you can see, the distribution is characterized by normal kurtosis and negative asymmetry.

Among the components of the religious value-emotional sphere, the claims of variation in the values of university students are not observed. The rates for each statement are high; the level of deviation from the total RCEC is a $=0.22$ points. At the same time, students see the greatest significance in "Having spiritual support in God" (emotional sphere) $=6.80$ points, and the least in "Doing things in the name of God" $=6.09$ points.

This means a high degree of internal consistency. More precisely, the religious valueemotional consistency of the personality shows a tendency to fairly consistently evaluate the significance of its components. 


\section{Conclusion}

1. The value-emotional sphere of the personality in the context of religious faith determines the subjective significance and meaning of the phenomena of reality.

2. The expressed religious value-emotional sphere of the personality, as a rule, corresponds to the canons of religion. In real-life situations of frustration, future clerics, and believers living in the world exhibit ambiguous behavioral responses. The theoretical significance of the study lies in the results of the study of the valueemotional sphere of the personality obtained in a specific category of subjects. The study enriches scientific knowledge in the field of personality psychology and psychology of religion. Its results can be used to build a psychological concept of a religious personality.

The practical significance of the study can also be identified. The research materials can be used to develop methodological tools to diagnose the psychological characteristics of believers. The specificity of the value-emotional sphere of a person in the context of religious faith can be considered in the practical work of a psychologist with believers, as well as in the educational and training work of spiritual educational institutions.

\section{Bibliographic references}

ALLEN, D. 2005. Phenomenology of religion. In J. Hinnells (ed.), The Routledge companion to the study of religion. London - New York: Routledge, pp. 182-207.

ALLPORT, G.W. 1963. Behavioral Science, Religion and Mental Health. In: Journal of Religion and Health, n. 2, pp. 187-197.

ALSTON, W.P. 1998. Religion, History of Philosophy. In: E. Craig (ed.). Routledge Encyclopedia of Philosophy, Vol. 8. New York: MacMillan, pp. 238-248.

BARANNIKOV, V.P. - MATRONINA, L.F. 2014. Sharing Our Lives Online: Risks and Exposure in Social Media. Palgrave Macmillan.

BLANSHARD, B. 1974. Reason and Belief. London: Allen \& Unwin.

BRAITHWAITE, R. 1955. An Empiricist's View of the Nature of Religious Belief. Cambridge: Cambridge University Press.

CHISHOLM, R. 1977. Theory of Knowledge. New York: Prentice-Hall.

EVANS, R.I. 2003. Some theoretical models and constructs generic to substance abuse prevention programs for adolescents: Possible relevance and limitations for problem gambling. In: Journal of gambling studies, vol. 19, n. 3, pp. 287-302.

FLURNUA, T. 2001. Principles of religious psychology. In: History of the psychology of religion: Reader. Kurgan, pp. 59-82.

HEATH, D.H. 1993. Personality roots of well-being, religiosity, and its handmaidenvirtue. Journal of religion and health, vol. 32, n. 4, pp.237-251.

HOGG, M.A. - VAUGHAN, G.M. 1995. Social psychology: An introduction. Harvester Wheatsheaf.

HUNT, S. 1998. Magical moments: an intellectualist approach to the neo-Pentecostal faith ministries. In: Religion, vol. 28, n. 3, pp. 271-280.

IGNATENKO, L.M. 2001. Feelings and religion. Minsk: Academic Publishing house. JAMES, W. 1917. Variety of religious experience: A Study in Human Nature (Being the Gifford Lectures on Natural Religion Delivered at Edinburgh in 1901-1902). London - New York: Longman. Made available by Project Guttenberg, Available online: https://www.gutenberg.org/files/621/621-pdf.pdf.

KHODZHAEVA, E.A. - SHUMILOVA, E.A. 2003. Religious rebirth and ethnic identity of Tartar youth in the Republic of Tatarstan. Almaty: Mezhdunarodnaya Kniga.

KUTSENYUK, B.M. 2007. Emotions and religion. 2nd ed. Kiev: Academic Pub. House. 
LEEVIK, G.E. 2000. Guide to the method of studying the value orientation of the individual. Leningrad: Znanie RSFSR.

LOVINGER, R.L. 2000. Religion and counseling. Psychological impact of religious belief. New York: Continuum.

MASLOW, A.H. 2013. Toward a psychology of being. Simon and Schuster.

MIEDEMA, S. 2014. "Coming out religiously!” Religion, the public sphere, and religious identity formation. In: Religious Education, vol. 109, n. 4, pp. 362-377.

PARYGIN, B.D. - ERUNOV, B.A. - BUKIN, V.R. 1971. Religious mood and its structure. Questions of scientific atheism. Moscow: Institute of Scientific Atheism.

PRATT, J.B. 2006. The religious consciousness. New York: Cosimo, Inc..

PÜNJER, G.C. 1880. Geschichte der Christlichen Religionsphilosophie seit der Reformation, Bd. I. Bis auf Kant. Braunschweig.

RIBOT, T. 2002. Illness of personality. Experience the study of creative imagination. Psychology of feelings. Minsk.

SPRANGER. 1928. Spranger, E., 1928. Types of men. The psychology and ethics of personality. Berlin: Niemeyer.

Words: 4710

Characters: $31338(17,41$ standard pages)

Shugyla Duanaeva

Nur-Mubarak Egyptian Islamic University of the Religious studies department, al Farabi street 72

Kazakhstan

zhanat_2006@mail.ru

Yerzhan Kalmakan

Nur-Mubarak Egyptian Islamic University

Head of the Department of Religious Studies

al Farabi street 72, City Almaty

Kazakhstan

bislauka@mail.ru

Amrekul Abuov

Akhmet Yassawi International Kazakh-Turkish University

Auezov street,48, Turkestan city

Kazakhstan

zurazhan88@mail.ru

Shuga Abeuova

UIB (University of International Business)

Abay 8a, City Almaty

Kazakhstan

nurzhanzhan@mail.ru

Tolen Barakbayeva

Nur-Mubarak Egyptian Islamic University

Department of Religious Studies

al Farabi street 72

Kazakhstan

nurbeklunara@mail.ru 